\title{
Diagnosis of Anxiety Disorders in University Students through the Early Maladaptive Schemas and Beck's Inventory
}

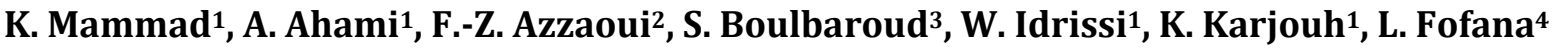 \\ ${ }^{1}$ Unit of Clinical and Cognitive Neuroscience and Nutritional Health, Department of Biology, Faculty of Science, \\ Kenitra, Morocco \\ ${ }^{2}$ Laboratory of Biology and Health, Department of Biology, Faculty of Science Ben M'Sik, Hassan II University, \\ Casablanca, Morocco \\ ${ }^{3}$ Department of Biology, Polydisciplinary Faculty, Sultan Moulay Sliman University, \\ Beni Mellal, Morocco \\ ${ }^{4}$ Therapy Cognitive-Behavioral, Charles-De-Gaulle University, Lille, France \\ Email: khaoula.mammad@gmail.com
}

How to cite this paper: Mammad, K., Ahami, A., Azzaoui, F.-Z., Boulbaroud, S., Idrissi, W., Karjouh, K., \& Fofana, L. (2017). Diagnosis of Anxiety Disorders in University Students through the Early Maladaptive Schemas and Beck's Inventory. Psychology, 8, 2114-2125.

https://doi.org/10.4236/psych.2017.813134

Received: October 7, 2017

Accepted: November 10, 2017

Published: November 13, 2017

Copyright $\odot 2017$ by authors and Scientific Research Publishing Inc. This work is licensed under the Creative Commons Attribution International License (CC BY 4.0).

http://creativecommons.org/licenses/by/4.0/

\section{c. (i) Open Access}

\begin{abstract}
Aim is to diagnose the prevalence of anxiety disorders using early maladaptive schemas and Beck's anxiety inventory among students. The present study is a cross-sectional study conducted among 212 students, aged 17 to 25 years, randomly selected from different institutions of the IBN TOFAIL University, located in the city of Kenitra (NW of Morocco). Two neurocognitive tests were used: The Beck Anxiety Inventory to evaluate anxiety \& the short version of the early maladaptive schema questionnaire of Schmidt, Joiner, Young and Telch (1995) which was translated in French by Rusinek \& Hautekéete (2000) to evaluate schemas. The obtained results of measure of anxiety show that the inadequate early maladaptive schemas positively correlated with the Beck Anxiety Inventory: Emotional deprivation $(\mathrm{r}=0.1635, p<0.05)$ Isolation $(\mathrm{r}=$ $0.2305, p=0.001)$ and Insufficient self-control $(\mathrm{r}=0.1819, p<0.01)$, Abandon $(\mathrm{r}=0.2514, p=0.001)$ Vulnerability $(\mathrm{r}=0.1505, p<0.05)$, Fear of losing control $(\mathrm{r}=0.1510, p<0.05)$. A band appears between early maladaptive schemas and Beck anxiety inventory revealing the existence of anxiety in university students, which has appeared in some maladaptive schemas, especially: Emotional deprivation, Isolation, Insufficient self-control, Abandon, Vulnerability, Fear of losing control. Deeper investigations needed to understand this relationship and to study other possible factors that could affect this important neurocognitive function.
\end{abstract}




\section{Keywords}

Early Maladaptive Schemas, Beck Anxiety Inventory, Anxiety, Students, Diagnosis, Relationship

\section{Introduction}

Anxiety disorders are the most common psychic disorders and include various psychological disorders such as Anxiety Disorders (separation anxiety disorder, selective mutism, specific phobia, social phobia, panic disorder, agoraphobia, and generalized anxiety disorder), Obsessive-Compulsive-Disorders (obsessive-compulsive disorder, body dysmorphic disorder, hoarding disorder, trichotillomania, and excoriation disorder), and also Trauma and Stressor-Related Disorders (reactive attachment disorder, disinhibited social engagement disorder, PTSD, acute stress disorder, and adjustment disorder) (American Psychiatric Association, 2013).

The management of anxiety disorders is different according to theoretical models; in this context, Young has developed a model of therapy by the schemes (Young \& Brown, 1990). He gives the following definition: The schema represent a theme or an important and invasive model regarding to the individual and his relationships with others. They develop in childhood or adolescence, enrich and complicate throughout life. The schemas are formed of memories, emotions, thoughts, body sensations and evoke a notorious dysfunction (Young et al., 2003).

In their general principles, Schemas are knowledge structures stored in long term memory, which are built by successive integration of experiences and contain all the intimate beliefs and convictions of the subject itself and the world. When they are activated, they channel attention and they act as cognitive filters all throughout the process of information's treatment (Blackburn, 1988). They represent a permanent interaction between behaviors, emotions, attention and memory and are manifested by cognitive distortions and biases specific to each major type of psychopathology (Lutz \& Huitt, 2003).

In addition, anxiety is a universal and generally adaptive response to threat, but in some circumstances, it may become inadequate. Characteristics that distinguish pathological anxiety and appropriate anxiety include: anxiety out of proportion to the level of threat; persistence or severe deterioration associated with recurring panic attacks; severe physical symptoms; and abnormal beliefs such as thoughts of sudden death and perturbations of the patient's usual functioning. Additionally, anxiety disorders should be differentiated from stress reactions, in which anxiety may be a prominent feature.

Indeed, there are many types of anxiety disorders:

- Panic disorder: Sudden bursts of extreme anxiety that is accompanied by symptoms like a pounding heart, sweaty palms, and shortness of breath or nausea.

- Agoraphobia: Anxiety about being in places or situations from which it is 
difficult to escape when a panic attack should occur.

- Social phobia (also called social anxiety disorder): Strong fear of social interaction or performance situations because of the potential for embarrassment of humiliation.

- Generalized anxiety disorder: Long periods of uncontrollable worry about everyday issues or events, which is typically accompanied by feelings of tiredness, restlessness or difficulty concentrating.

- Posttraumatic stress disorder: Recurrent and intrusive memories of a trauma, feelings of emotional numbing and detachment, and increases in emotional arousal, such as irritability and disturbed sleep, resulting from a previous traumatic event.

- Obsessive-compulsive disorder: Repeated thoughts, images or impulses that the person feels are inappropriate, and repetitive behaviors are designed to reduce the anxiety generated by the thoughts (National Institutes of Mental Health, 2016).

Studies of university students using early maladaptive schemas (EMS) are few in number except those (Isanejad, 2012; Shaikhahmadi, 2015). However, those on Moroccan students currently limit only in those of the neurocognition unit of the department of our university (Ahami, Mammad et al., 2017) which evaluates the impact of early maladaptive schemas in memory and cognitive performance of students.

The objective of this work is to diagnose the prevalence of anxiety disorders using early maladaptive schemas and Beck's anxiety inventory (BAI) among students.

\section{Subjects, Materials, and Methods}

\subsection{Subjects}

Our study realized during May-June 2013, among 212 Moroccan students aged between 17 and 21 years, is a descriptive cross-sectional where we used a structured questionnaire. with the different specialties in the University Ibn-Tofail: Faculty of Sciences (50\%), Faculty of Letters \& Human Sciences (30\%), Faculty of Law and Economic Sciences (8\%) and National School of Applied Sciences (ENSA) (7\%).

\subsection{Materials}

Two questionnaires are used in this study:

- Questionnaire of early maladaptive schemas short version of Young translated by Rusinek \& Hautekéete to frensh (2000), 13 schemas.

- Beck Anxiety Inventory (BAI)

\subsection{Methods}

Elaboration of the tests:

Questionnaire of early maladaptive schemas for Adult: 
The questionnaire about EMSs of anxiety consists of 65 statements such as "Nobody really understands me", which are asked to respond by circling a number ranging from one to six (when the number is high then the person considers that the statement corresponding).

We have 13 schemas, which we used:

- Abandonment: Five items on the feeling that appreciated relationships with others will stop as always.

- Mistrust: Five items related to mistrust towards others.

- Emotional deprivation: Five items representing past and present complaint about the lack of emotional sharing with others, the lack of consideration and affection.

- Social isolation: Five items on the themes of loneliness, rejection of others, inability to invest in social relations.

- Dependence: Five items on the need of others to understand what is happening and perform actions.

- Vulnerability: Five items for fear of impending disaster.

- Insufficient self-control: Seven items that linked by easy nervousness, unwillingness to complete the tasks, the refusal to act against his/her will.

- Self-sacrifice: Five items on unlimited devotion to others.

- Emotional inhibition: 5 items related to the inability to express feelings

- Unrelenting standards: Five items whose main themes are the desire of perfection for oneself, inability to be satisfied by actions.

- Incompetence: Five items on the theme of belief in ability level and lower than that of other successful

- Enmeshment; Five items on the inability to break away from the opinion and influence of parents and partners.

- Fear of loss of control: Five items on fear to react impulsively and hurt others physically or morally.

Beck Anxiety Inventory (BAI):

Respondents are asked to report the extent to which they have been bothered by each of the 21 symptoms in the week preceding (including the day of) their completion of the BAI.

Each symptom item has four possible answer choices: Not at all; mildly (It did not bother me much); moderately (It was very unpleasant, but I could stand it), and; severely (I could barely stand it). The clinician assigns the following values to each response: Not at All $=0$; Mildly $=1$; Moderately $=2$, and; Severely $=3$. The values for each item summed yielding an overall or total score for all 21 symptoms that can range between 0 and 63 points. A total score of $0-7$ is interpreted as a "Minimal" level of anxiety; 8 - 15 as "Mild"; 16 - 25 as "Moderate", and; 26 - 63 as "Severe". Clinicians examine specific item responses to determine whether the symptoms appear mostly subjective, neurophysiologic, autonomic, or panic-related. The clinical can then further assess using DSM criteria to arrive at a specific diagnostic category and plan interventions targeting the underlying cause of the respondent's anxious symptomatology and/or diagnosis (Beck \& Steer, 1990). 


\section{Introduction of tests:}

The survey conducted during the period May, June 2013. We made various tests in a random manner, students interviewed in their classrooms and completed the questionnaire and other tests took place individually or in groups of 2 to 5 participants, after asking them the question at the same time read it aloud and explain one or more times for each one, and then record all results.

\section{Statistical Analysis}

The descriptive study is realized using calculation of frequency, and the correlation between the early maladaptive schemas and Digit span and the number of Units which the student validated in his first year at university, they were evaluated using of the Spearman's correlation coefficient $\rho$.

\section{Results}

\section{Distribution and Variation of EMS and BAI:}

As it shows the graphs below, the mean for the test of BAI is $15.75 \pm 9.93$ it shows that our sample has a middling anxiety (Figure 1).

Means are presented in graphs bellow of EMS. We remark that there are some schemas which are activated and others not: Fear of loss control (4.30 \pm 1.38$)$; Unrelenting standards $(4.28 \pm 1.35)$; Mistrust $(3.73 \pm 1.30)$; Insufficient selfcontrol (3.59 \pm 1.19$)$; Self-sacrifice $(3.51 \pm 1.20)$; Enmeshment $(3.45 \pm 1.18)$ Emotional deprivation ( $3.30 \pm 1.31)$; Vulnerability $(3.23 \pm 1.43)$; Abandonment (3.23 \pm 1.36$)$; Emotional inhibition (3.09 \pm 1.30$)$; Incompetence $(2.88 \pm 1.20)$; Dependence $(2.77 \pm 1.43)$; Social isolation (2.55 \pm 1.24$)$ (Figure 2).

Preliminary analysis as shown the results found in our sample: (Figure 3): the percentage of Minimal anxiety was $21 \%$, Mild anxiety was 34\%, Moderate anxiety $27 \%$, and finally Severe anxiety $18 \%$.

\section{Statistic study:}

Statistical study between EMS \& BAI \& Digit spans and shows as a result of correlation (Table 1).

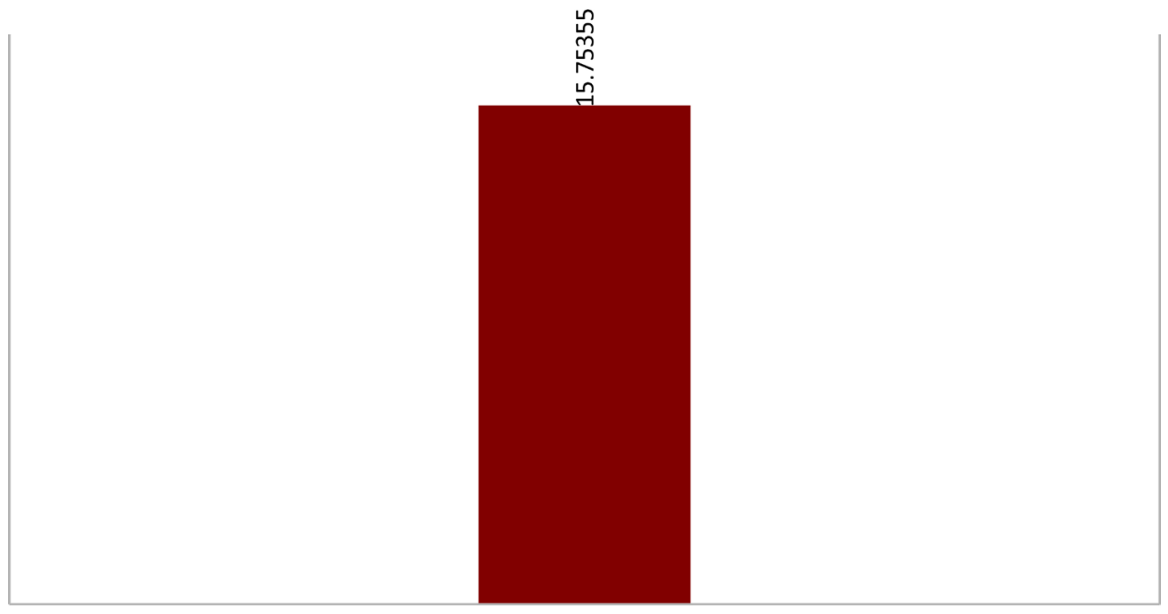

Figure 1. Mean of Beck anxiety inventory. 


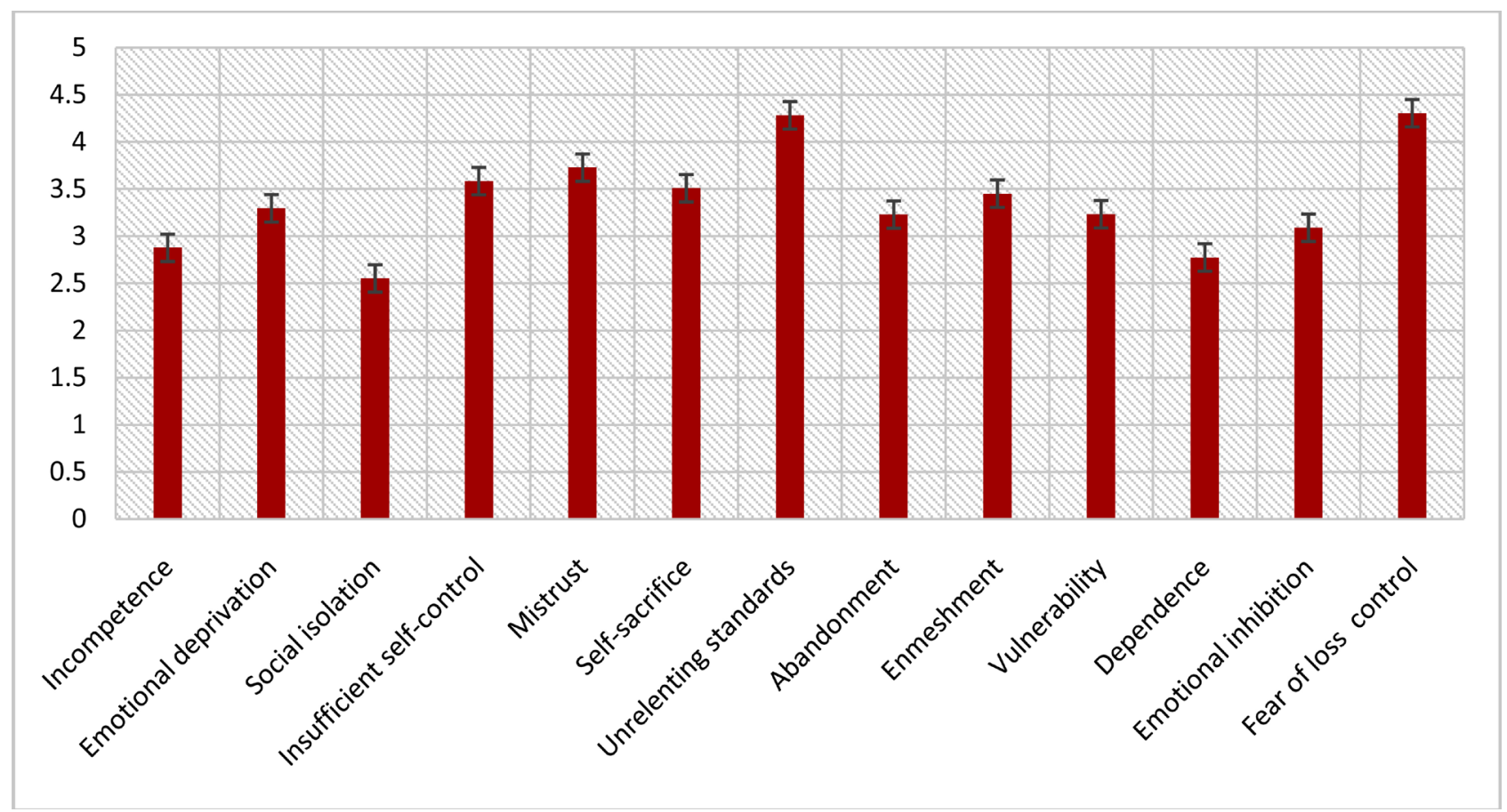

Figure 2. Mean of different schemas.

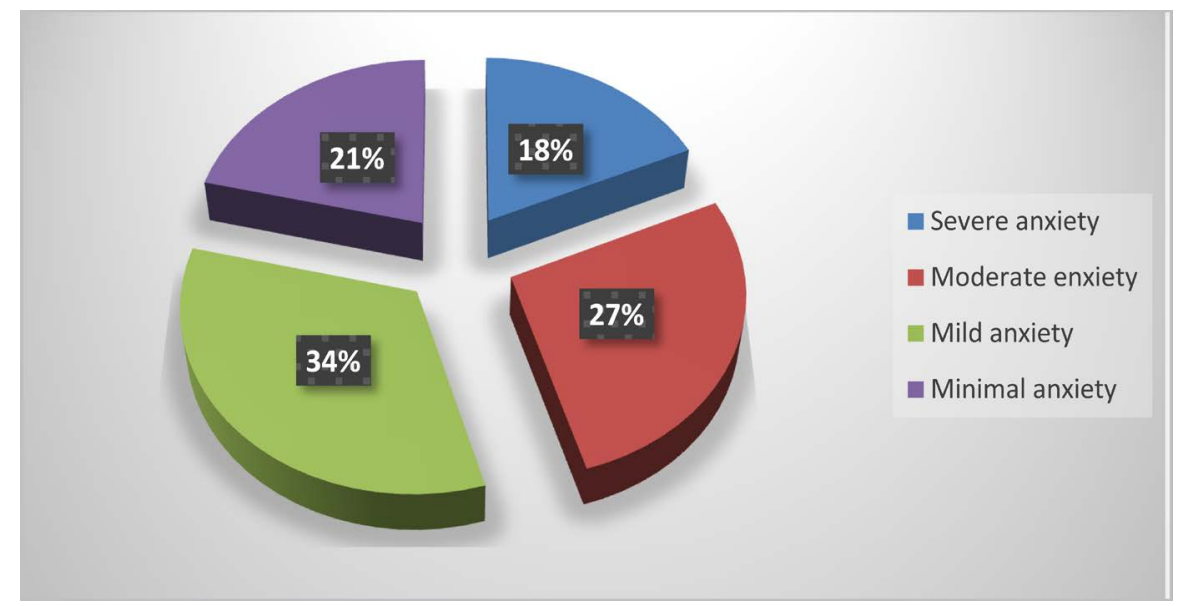

Figure 3. Distribution of BAI's result.

Correlations (Spreadsheet 1) Marked correlations are significant at $p<0.05$.

The observation of the statistical results indicates that the evolution of some schemas influenced the evolution of anxiety disorder. Statistical analysis by using the correlation showed that the EMSs positively correlated with the inventory of Beck anxiety. And that is clearly apparent in the following Schemas: Emotional deprivation $(\mathrm{r}=0.1635 ; p<0.05)$; Social isolation $(\mathrm{r}=0.2305, p=0.001)$ et insufficient self-control $(\mathrm{r}=0.1819 ; p<0.01)$; Abandonment $(\mathrm{r}=0.2514 ; p=$ $0.001)$. Vulnerability $(\mathrm{r}=0.1505 ; p<0.05)$. Fear of loss control $(\mathrm{r}=0.1510 ; p<$ $0.05)$.

There is also a significant correlation between the different schemas. We remark in Table 2 a positive correlation. 


\section{Discussion}

The activation of certain schemas influenced the development of anxiety disorders among students as the BAI test indicate, we have those who have interpreted anxiety, \& minimal anxiety, \& mild anxiety, and those with moderate \& severe anxiety (Figure 3 ), the mean for the test of BAI is $15.75 \pm 9.93$ it shows that our sample has a middling anxiety (Figure 1).

The first element of this statement joins the theoretical position of Beck (Beck \& Emery, 1985; Beck \& Freeman, 1990) which means that anxiety is actually a mode consists of many schemas position illustrated in children by the study of Leung and Poon (2001). Since we have targeted the negative impact of schemas on memory (Ahami, Mammad et al., 2017), in the current study our objective is to evaluate the anxiety of the students, where we selected from several tests that of BAI and EMS because they are among the most reliable according to the international literature on anxiety.

The obtained results of measure of anxiety show that, the EMS positively correlated with the BAI: Emotional deprivation Isolation and Insufficient self-control, Abandon Vulnerability, Fear of losing control (Table 1). BAI and its four factor scores compared to individuals with a primary diagnosis of generalized anxiety disorder (GAD), specific or social phobia, panic disorder with or without agoraphobia, obsessive-compulsive disorder (OCD), and no psychiatric diagnosis. However, according to the study of Cousineau (2004), establishes the relationship between anxiety and early maladaptive schemas, this result seems questionable. In this research, the schemas classified into three categories: The EMS including anxiety in their definition: "Vulnerability", diagrams referring to a loss or a relational crisis: "Abandonment, Dependence, Mistrust, Social isolation, and Schemas related to a potential loss of integrity of the Self: Enmeshment, Emotional inhibition, Unrelenting Standards".

This nomenclature leaves only four schemas with a more distant relationship with anxiety: the emotional deprivation schemas with its dominant cravings; Self-sacrifice associated with guilt; while Fear of loss control and insufficient self-control often characterized by the absence of anxiety. This guide to say, that anxiety is often an indicator of non-specific malaise that requires further evaluation. In our result the schema including anxiety in its definition: Vulnerability is active but ranked seventh after (Fear of loss control, Unrelenting standards, insufficient self-control, Self-sacrifice, Enmeshment, Emotional deprivation) depending on the degree of activation in the students (Figure 2).

If we talk about the $2^{\text {nd }}$ group: schemas referring to a loss or a relationship crisis, We find that the Abandonment schema classified according to EMS's means after the $8^{\text {th }}$ schemas which is vulnerability, this schemas can provide very high levels of anxiety. About the both schemas: Social isolation and Dependence both activated in our sample.

Finally, the EMS related to potential loss of integrity of the Self: Enmeshment, Unrelenting standards, emotional inhibition schemas are activated (Figure 2). 
Otherwise, cognitive schemas considered having a key role in the development and maintenance of psychological disorders as well as in their recurrence and relapse, and so an understanding of schemas may help to explain vulnerability to psychopathology (Bamber \& McMahon, 2008; Wells, 1997). Furthermore, there is also a significant correlation between the different schemas; we remark a positive correlation (Table 2). Beck (1976) considered that maladaptive schemas reflect deeply rooted patterns of distorted thinking about the world, oneself and one's relationship with others (Muris, 2006). Schemas considered being highly generalized, resistant to change and exerting a strong influence over cognition and affect, and this influence exerted through information processing at the unconscious level (Riso \& McBride, 2007).

Table 1. The correlation between the EMSs and BAI.

\begin{tabular}{|c|c|}
\hline & Beck anxiety Inventory \\
\hline \multirow[t]{2}{*}{ Incompetence } & $\mathrm{r}=0.1015$ \\
\hline & $p>0.05$ \\
\hline \multirow[t]{2}{*}{ Emotional deprivation } & $\mathrm{r}=0.1635$ \\
\hline & $p<0.05$ \\
\hline \multirow[t]{2}{*}{ Social isolation } & $\mathrm{r}=0.2305$ \\
\hline & $p=0.001$ \\
\hline \multirow[t]{2}{*}{ Insufficient self-control } & $\mathrm{r}=0.1839$ \\
\hline & $p<0.01$ \\
\hline \multirow[t]{2}{*}{ Mistrust } & $\mathrm{r}=0.0108$ \\
\hline & $p>0.05$ \\
\hline \multirow[t]{2}{*}{ Self-sacrifice } & $\mathrm{r}=0.0263$ \\
\hline & $p>0.05$ \\
\hline \multirow[t]{2}{*}{ Unrelenting standards } & $\mathrm{r}=0.0125$ \\
\hline & $p>0.05$ \\
\hline \multirow[t]{2}{*}{ Abandonment } & $\mathrm{r}=0.2514$ \\
\hline & $p=0.001$ \\
\hline \multirow[t]{2}{*}{ Enmeshment } & $\mathrm{r}=0.1217$ \\
\hline & $p>0.05$ \\
\hline \multirow[t]{2}{*}{ Vulnerability } & $\mathrm{r}=0.1505$ \\
\hline & $p<0.05$ \\
\hline \multirow[t]{2}{*}{ Dependence } & $\mathrm{r}=0.0889$ \\
\hline & $p>0.05$ \\
\hline \multirow[t]{2}{*}{ Emotional Inhibition } & $\mathrm{r}=0.1301$ \\
\hline & $p>0.05$ \\
\hline \multirow[t]{2}{*}{ Fear of loss control } & $\mathrm{r}=0.1510$ \\
\hline & $p<0.05$ \\
\hline
\end{tabular}


Table 2. Correlation between different schemas.

\begin{tabular}{|c|c|c|c|c|c|c|}
\hline & $\begin{array}{c}\text { Emotional } \\
\text { deprivation }\end{array}$ & $\begin{array}{l}\text { Insufficient } \\
\text { self-control }\end{array}$ & Self-sacrifice & Abandonment & Vulnerability & $\begin{array}{l}\text { Emotional } \\
\text { inhibition }\end{array}$ \\
\hline \multirow{2}{*}{ Incompetence } & $\mathrm{r}=0.3473$ & $\mathrm{r}=0.2792$ & $\mathrm{r}=0.1298$ & $\mathrm{r}=0.3799$ & $\mathrm{r}=0.0843$ & $\mathrm{r}=0.1035$ \\
\hline & $p<0.001$ & $p<0.001$ & $p=0.059$ & $p<0.001$ & $p=0.222$ & $p=0.133$ \\
\hline \multirow{2}{*}{ Social isolation } & $\mathrm{r}=0.2585$ & $\mathrm{r}=0.2469$ & $\mathrm{r}=0.19$ & $\mathrm{r}=0.3824$ & $\mathrm{r}=0.0045$ & $\mathrm{r}=0.104$ \\
\hline & $p<0.001$ & $p=0.000$ & $p=0.006$ & $p<0.001$ & $p=0.949$ & $p=0.131$ \\
\hline \multirow{2}{*}{ Mistrust } & $\mathrm{r}=0.2339$ & $\mathrm{r}=0.3415$ & 0.0451 & $\mathrm{r}=0.1982$ & $\mathrm{r}=0.0365$ & $\mathrm{r}=0.0919$ \\
\hline & $p=0.001$ & $p<0.001$ & $p=0.514$ & $p<0.01$ & $p=0.598$ & $p=0.182$ \\
\hline \multirow{2}{*}{$\begin{array}{l}\text { Unrelenting } \\
\text { standards }\end{array}$} & $r=0.2287$ & $\mathrm{r}=0.2895$ & $r=0.137$ & $r=0.1813$ & $r=0.032$ & $\mathrm{r}=-0.0272$ \\
\hline & $p=0.001$ & $p<0.001$ & $p<0.05$ & $p<0.01$ & $p=0.643$ & $p=0.693$ \\
\hline \multirow{2}{*}{ Enmeshment } & $\mathrm{r}=0.145$ & $r=0.2935$ & $\mathrm{r}=0.1717$ & $\mathrm{r}=0.2827$ & $\mathrm{r}=0.0037$ & $\mathrm{r}=0.0123$ \\
\hline & $p<0.05$ & $p<0.001$ & $p<0.05$ & $p<0.001$ & $p=0.957$ & $p=0.858$ \\
\hline \multirow{2}{*}{ Dependence } & $\mathrm{r}=0.1204$ & $\mathrm{r}=0.2018$ & $\mathrm{r}=0.0382$ & $\mathrm{r}=0.2221$ & $\mathrm{r}=0.5545$ & $\mathrm{r}=0.3064$ \\
\hline & $p=0.080$ & $p<0.01$ & $p=0.580$ & $p=0.001$ & $p<0.001$ & $p<0.001$ \\
\hline \multirow{2}{*}{$\begin{array}{c}\text { Fear of loss } \\
\text { control }\end{array}$} & $\mathrm{r}=0.0982$ & $\mathrm{r}=0.0021$ & $\mathrm{r}=0.0608$ & $\mathrm{r}=0.0724$ & $\mathrm{r}=0.2838$ & $\mathrm{r}=0.1127$ \\
\hline & $p=0.154$ & $p=0.975$ & $p=0.379$ & $p=0.294$ & $p<0.001$ & $p=0.102$ \\
\hline
\end{tabular}

In general, terms, a schema can be defined by a structure, framework, theme, or pattern of cognitive content (Whisman \& Uebelacker, 2006). Therefore, a schema can thought by a blueprint imposed on experience to help individuals explain it, to mediate perception, and to guide responses (Young \& Brown, 1990, 1999; Young et al., 2003). Schemas are thought to develop during childhood in the interpersonal context of a person's primary relationships, and reflect schemas of meaning derived from those experiences (Welburn, Coristine, Dagg, \& Pontefract, 2002).

Young and colleagues distinguish between 18 EMSs that organized in five domains, which correspond to the frustration of five basic psychological needs in childhood: secure attachment, autonomy, realistic limits, self-directedness, and playfulness (Rafaeli et al., 2011).

The EMSs that are more active more related to guilt, but isn't directly related to the anxiety that seems to require a more sensitive assessment. However, we can also think that the self-sacrifice scheme entails certain fragility because of self-sacrifice that must be made about the pushing and symptoms of anxiety or depression.

The existence of schemas obviates the need to mentally reinvent the wheel with each new experience, so incoming information can be compared and filtered (Dalgleish, 2004). Schemas act as screening templates to determine what is processed, and there by distort and bias the understanding of information (McBride, Farvolden, \& Swallow, 2007; Young \& Brown, 1990). Research indicates that information processing biased in favor of maintaining the status with respect to schema content. For example, according to Young et al. (2003), people 
are relatively better at remembering schema-consistent information, tend to make errors in a schema-consistent pattern, and interpret new information to support pre-existing schemas.

As a self-report measure for the assessment of EMSs, the Young Schema Questionnaire (YSQ) and a short form (YSQ-SF) have been constructed. The YSQ-SF is based on a factor-analytic study of the YSQ (Schmidt, Joiner, Young, \& Telch, 1995) and covers 15 of the 18 EMSs on the current schema list (Young et al., 2003). But in our research we used the short version of the early maladaptive schema questionnaire of Schmidt, Joiner, Young and Telch (1995) which was translated in French by Rusinek \& Hautekéete (2000) contain 13 schemas: Abandonment; Mistrust; Emotional deprivation; Social isolation; Dependence; Vulnerability; Insufficient self-control; Self-sacrifice; Emotional inhibition; Unrelenting standards; Incompetence; Enmeshment; Fear of loss of control.

Furthermore, Young (1999) postulated five core emotional needs for human beings: Secure attachments to others (includes safety, stability, nurturance, and acceptance), Autonomy, competence, and sense of identity, Freedom to express valid needs and emotions, Spontaneity and play, Realistic limits and self-control. These considered universal; a psychologically healthy individual is one who can adaptively meet these core emotional needs. Early maladaptive schemas may result from a frustration of these basic needs by interaction between the child's innate temperament and dysfunctional experiences with parents, siblings, and peers during the first few years of life (Hoffart et al., 2005; Torres, 2002).

\section{Conclusion}

Deeper investigations needed to understand this relationship and to study other possible factors that could affect this important neurocognitive function. These results lead us to the establishment by the competent authorities within the University of medico-psychological Center of psychological care of these students. Such monitoring would disable these anxiety's schemas and prevent deterioration of their mental health.

\section{References}

Ahami, A., Mammad, K., Azzaoui, F.-Z., Boulbaroud, S., Rouim, F.-Z., \& Rusinek, S. (2017). Early Maladaptive Schemas, Working Memory and Academic Performances of Moroccan Students. Open Journal of Medical Psychology, 6, 53-65.

American Psychiatric Association. (2013). Diagnostic and Statistical Manual of Mental Disorders. Arlington, VA: American Psychiatric Publishing.

Bamber, M., \& McMahon. (2008). R: Danger-Early Maladaptive Schemas at Work!: The Role of Early Maladaptive Schemas in Career Choice and the Development of Occupational Stress in Health Workers. Clinical Psychology \& Psychotherapy, 15, 96-112.

Beck, A. (1976). Cognitive Therapy and Emotional Disorders. New York: International Universities Press.

Beck, A. T., \& Emery, G. (1985). Anxiety Disorders and Phobias: A Cognitive Perspective. Basic Books/Harper Collins Publishers, New York. 
Beck, A. T., \& Freeman, A. (1990). Cognitive Therapy of Personality Disorders. The GuilfordPress, New York.

Beck, A. T., \& Steer, R. A. (1990). Manual for the Beck Anxiety Inventory. San Antonio, TX: Psychological Corporation.

Blackburn, I. M., \& Cottraux, J. (1988). Thérapie cognitive de la dépression. [Cognitive Therapy of Depression.] Paris: Masson.

Cousineau, P. (2004). Y a-t-il des schémas précoces inadaptés prédisposant à l'anxiété? [Are There Early Maladaptive Schemas Predisposing to Anxiety?] SantMentQue, 29, 53-60.

Dalgleish, T. (2004). Cognitive Approaches to Post-Traumatic Stress Disorder: The Evolution of Multirepresentational Theorizing. Psychological Bulletin, 130, 228-260.

Hoffart, A., Sexton, H., Hedley, L. M., Wang, C. E., Holthe, H., Haugum, J. A. et al. (2005). The Structure of Maladaptive Schemas: A Confirmatory Factor Analysis and a Psychometric Evaluation of Factor-Derived Scales. Cognitive Therapy and Research, 29, 627-644. https://doi.org/10.1007/s10608-005-9630-0

Isanejad, O., Heidary, M. S., Rudbari, O., \& Liaghatdar, M. J. (2012). Early Maladaptive Schemes and Academic Anxiety. World Applied Sciences Journal, 18, 107-112.

Leung, P. W. L., \& Poon, M. W. L. (2001). Dysfunctional Schemas and Cognitive Distortions in Psychopathology: A Test of the Specificity Hypothesis. Science, 283, 1657-1661.

Lutz, S., \& Huitt, W. (2003). Information Processing and Memory: Theory and Applications. Educational Psychology Interactive. Valdosta, GA: Valdosta State University.

McBride, C., Farvolden, P., \& Swallow, S. R. (2007). Major Depressive Disorder and Cognitive Schemas. In L. P. Riso, P. L. du Toit, D. J. Stein, \& J. E. Young (Eds.), Cognitive Schemas and Core Beliefs in Psychological Problems: A Scientist-Practitioner Guide (pp. 11-39). Washington DC: American Psychological Association.

Muris, P. (2006). The Pathogenesis of Childhood Anxiety Disorders: Considerations from a Developmental Psychopathology Perspective. International Journal of Behavioural Development, 30, 5-11.

National Institutes of Mental Health. (2016). Anxiety Disorder? https://www.nimh.nih.gov/health/topics/anxiety-disorders/index.shtml

Rafaeli, E, Bernstein, D. P., \& Young, J. (2011). Schema Therapy (184 p). UK: Routledge, Taylor \& Francis Group.

Riso, L. P., \& McBride, C. (2007). Introduction: A Return to a Focus on Cognitive Schemas. In L. P. Riso, P. L. Du Toit, D. J. Stein, \& J. E. Young (Eds.), Cognitive Schemas and Core Beliefs in Psychological Problems: A Scientist Practitioner Guide (pp. 3-9). Washington DC: American Psychological Association.

Rusinek, S., \& Hautekéete, M. (2000). Instrument d'étude des schémas précoces pour enfants (ISPE). [Instrument for Studying Early Schemas for Childhood.] Journal de Thérapie Comportementale et Cognitive, 9, 55-61.

Schmidt, N. B., Joiner, T. E., Young, J. E., \& Telch, M. J. (1995). The Schema Questionnaire: Investigation of Psychometric Properties and the Hierarchical Structure of a Measure of Maladaptive Schemata. Cognitive Therapy and Research, 19, 295-321. https://doi.org/10.1007/BF02230402

Shaikhahmadi, K., Sajjadi, S. A., \& Kalvandi, A. (2015). The Relationship between Early Maladaptive Schema with Academic Achievement and Mathematics Test Anxiety. Journal of Applied Environmental and Biological Sciences, 5, 63-69.

Torres, C. (2002). Early Maladaptive Schemas and Cognitive Distortions in Psychopathy and Narcissism. Unpublished Doctoral Dissertation, Canberra: Australian National 
University.

Welburn, K., Coristine, M., Dagg, P., Pontefract, A., \& Jordan, S. (2002). The Schema Questionnaire-Short Form: Factor Analysis and Relationship between Schemas and Symptoms. Cognitive Therapy and Research, 26, 519-530.

https://doi.org/10.1023/A:1016231902020

Wells, A. (1997). Cognitive Therapy of Anxiety Disorders: A Practice Manual and Conceptual Guide. Chichester: Wiley.

Whisman, M. A., \& Uebelacker, L. A. (2006). Impairment and Distress Associated with Relationship Discord in a National Sample of Married or Cohabiting Adults. Journal of Family Psychology, 20, 369-377. https://doi.org/10.1037/0893-3200.20.3.369

Young, J. (1999). Cognitive Therapy for Personality Disorders: A Schema-Focused Approach (3rd ed.). Sarasota, FL: Professional Resource Exchange.

Young, J. E., \& Brown, G. (1990). Young Schema Questionnaire. New York: Cognitive Therapy Center of New York.

Young, J. E., Klosko, J. S., \& Weishaar, M. E. (2003). Schema Therapy: A Practitioner's Guide. New York: Guilford. 